\title{
A Prospective Study on the Efficacy of Closed Suction Drains in Fractures of the Hip Treated by Dynamic Hip Screw
}

\author{
Shareef S M Nada ${ }^{1,3 *}$, Dalia A E Abuzeid ${ }^{2}$ and Hashim A Ahmed ${ }^{3}$ \\ ${ }^{1}$ Pediatric Orthopedics Fellow, Yonsei, South Korea \\ ${ }^{2}$ PgDip Research and Methodology, MRCP, UK \\ ${ }^{3}$ Department of Orthopedics, University of Khartoum, Sudan \\ *Corresponding Author: Shareef S M Nada, Department of Orthopedics, \\ University of Khartoum, Sudan.
}

Received: November 02, 2020

Published: November 27, 2020

(C) All rights are reserved by Shareef $\mathbf{S} \mathbf{M}$

Nada., et al.

\section{Abstract}

Background: The use of closed suction drains in orthopedics has been a subject of controversy over the years. The drain has a common and effective role in general surgery but its use in orthopedics has yet to be justified. This study aims to elucidate the effect of closed suction drainage on the outcome of the extracapsular fractures of the neck of femur treated by DHS.

Methods: 160 patients were included in the study. A non-randomized prospective cohort study design was used. There were two groups of 80 involved, which were all the patients undergoing DHS surgery in KTH from the period of Feb-June 2016. One group received a drain while the other did not, and the 2 groups were homogeneous in every respect other than the use of the drain. All the patients were followed up until 2 weeks postoperatively and appropriate statistical analysis methods were used.

Results: The mean age was $61 \pm 2.8 .51 \%$ of the fractures were intertrochanteric. The drains were removed after 72 hours in $63 \%$ of the drained group. $10 \%$ of the entire sample developed wound infections. Statistically significant postoperative complications were found in the drained group when compared to the non-drained group with a RR of 2 (95\% CI) especially for respiratory complications.

Discussion: This is the first study of its kind in Sudan. Compared to other studies which showed no statistically significant difference in the use or nonuse of drains, this study showed that the use of closed suction drains is twice more likely to result in a postoperative complication than the nonuse of a drain. Also, drains should be removed within 24 hours as recommended by Chandretaya., et al. Based on these findings, the use of post-operative surgical drains in DHS should be limited by Orthopedic surgeons in Sudan.

Keywords: Dynamic Hip Screw; DHS; Drain; Intertrochanteric; Fracture; Wound

\section{Abbreviations}

CI: Confidence Interval; CV: Cardiovascular; DHS: Dynamic Hip Screw; DM: Diabetes Mellitus; DVT: Deep Vein Thrombosis; KTH: Khartoum Teaching Hospital; RR: Relative Risk; SPSS: Statistical Package for Social Sciences; TKR: Total Knee Replacement.

\section{Introduction}

The use of surgical drains in thoracic and abdominal surgery has a long and effective history. This is especially noted in reducing hematoma formation, decreasing the incidence of infection, and local swelling. This dates back to 460 B.C. when Hippocrates decided to treat empyema formation with drains [1]. Since then, drains have evolved over the centuries until 1959 when the silicone rubber was invented and its advantages and merits reported by Santos [2].

Physicians in ancient Rome as far back as $1^{\text {st }}$ century A.D were using drains to treat ascites and deep abscesses. However, it was Ambrose Pare in the early $16^{\text {th }}$ century who introduced the drain 
to orthopedics. He used his "tentes" i.e. cannulated lead tubes, not only for drainage but also for wound care and debridement [1].

Until the middle of the $20^{\text {th }}$ century, only open systems working with gravity were used. After that, progression in the field of engineering allowed for the presence of tubing that resisted obstruction when suction was done. This was a major breakthrough as far as drains were concerned because it allowed for the creation of closed drainage systems. This had a major impact on wound contamination from the external environment. Consistently, continuous suction closed drainage systems showed reduced wound complications as compared to open systems [1].

Over the years, during the evolution of the drain, there became certain criteria for which a drain should fulfill in order to be effective. First of all, it should be soft, causing minimal damage to the surrounding tissue. It also should be smooth resulting in efficient evacuation and removal; as it also should be simple to manage by the patient and by the staff. Furthermore, in order not to introduce infection into the body, it should be sterile. Last but not least, it should be stable i.e. it should be inert, nonallergenic, and not biodegradable [2].

The rationale for using a drain postoperatively in general surgery has been based on its significance on postoperative outcome. Theoretically speaking, the drain, which is composed of a perforated plastic tube with low pressure suction, will evacuate a developing hematoma from the operative field and promote wound healing.

Hematoma formation has been known to produce a good media for bacterial growth and thereby increasing the incidence of postoperative infection. Hematomas also decrease tissue perfusion and increase the wound tension. Drains have been shown to extensively decrease hematoma formation as well as allow for drainage of any excess fluid - purulent or otherwise - to expedite the process of healing. Drains have also been shown to decrease local swelling postoperatively [3].

The use of closed-suction drains in orthopedics has become a common practice but without actually being validated. There is little evidence to support their use concerning the outcome of the patient i.e. the wound healing and its complications, complications to the patient...etc. [4].

\section{Literature Review}

Drains have become a mainstay of management in general surgery. Their use and effectiveness have been widely and thoroughly investigated within the realms of general surgery. The success that has been allotted to the use of drains postoperatively in general surgery has caused a tentative introduction into the world of orthopedics. So much so that it has become a general practice rather than "evidence-based medicine"; as reported by Chandrateya in his study "To drain or not to drain" [7]. He also noticed a discord between the literature and the actual practice of orthopedic surgeons. Apparently, most surgeons have drawn their own conclusions on how, why and when to use a drain [7]. There are no standard regulations or rules on the use or non-use of a postoperative drain, it is merely a matter of the operator's choice, surgical opinion and expertise [7].

This is also true in Sudan, where the use of surgical drains postoperatively in orthopedics has become a common surgical practice. There is no statistical data regarding the use of surgical drains postoperatively in Sudan. Generally speaking, most surgeons utilize a drain for a period of 48 hours maximum. As it is commonly known, the majority of wound drainage occurs in the first 24 hours [7]. Any further use of a drain beyond 48 hours has been reported to cause more damage than good, as there is evidence of retrograde migration of bacteria from the skin through the drain. It has also been reported by Drinkwater and Neil that there is an increase in bacterial contamination in the tip of the drain after 24 hours [8]. This may cause a healthy clean wound site to become infected and failure of the procedure itself especially if a device e.g. DHS is used to stabilize the fracture.

Several studies have explored the issue of the duration of the drain insertion [3-6]. Most studies have concluded that drains should be removed after a period of 24 hours. The presence of the drain for longer than that has been shown to have unfavorable effects. Namely, there is an exponential increase in retrograde bacterial migration to the wound site. However, in regular practice, most surgeons $(69 \%)$ in these studies continue the drainage for more than 24 hours [5-7].

Over the last 15 years, the use of orthopedic drains has been questioned, leading to a number of randomized trials on the subject. A meta-analysis of studies regarding the use of closed suction drainage's benefits and disadvantages was performed at the 
Peterborough District Hospital, UK. This meta-analysis included 18 studies and 3495 patients. While it was concluded that further randomized trials with a larger sample size were required to fully analyze the presence or lack thereof of benefit of suction drainage, it was also reported that transfusion requirements were increased after total hip and knee arthroplasties [9]. One of the reasons of performing this meta-analysis was that in smaller studies, the sample size was questionably small thereby decreasing the power of the study itself. Thus, several studies have been conducted regarding the use of closed suction drainage postoperatively but always on a small scale.

A later study was conducted in the same hospital but using only 6 studies and showed no significant difference between the occurrence of wound healing complications, re-operations or transfusion requirement between drained and un-drained wounds [10].

One of the benefits of the drainage system is that the requirements for a postoperative dressing are decreased. A study performed in 2011 by Khanal., et al. showed a decrease in postoperative dressing requirements as opposed to the patients who weren't drained [11]. This benefit was thought to have more of a psychological impact on the patient. However, the study also failed to show a significant difference in postoperative wound infection rate [11].

Most of the studies available were centered on the use of suction drains in arthroplasty. Arthroplasty involves the opening of the joint capsule, which in itself is an excellent source of infection. ${ }^{12,13}$ This is why this study is concerned mostly about the use of the DHS, which does not involve the opening of the joint capsule and therefore, is associated with a decreased rate of infection.

The DHS is used to treat fractures of the neck of the femur. Fractures of the hip have been described as an orthopedic epidemic with an estimated global incidence of 1.3 million fractures in 1990. This is expected to increase to 4.5 million fractures by the year 2050 with the largest increase anticipated in Asia and Africa. Fractures of the neck of femur are divided into extra- and intracapsular. This study will be dealing with extra-capsular fractures of the neck of femur [14]. There are three subtypes of extra-capsular fractures which are treated via DHS: intertrochanteric, subtrochanteric and basal cervical.

Despite known limitations, femoral neck fractures in elderly patients are frequently described using the classification. In this age group, treatment can be recommended based on describing the fracture as non-displaced (Grade I, II) or displaced (Grade III, IV). The Garden classification is not as useful for describing femoral neck fractures in young adults. Pauwels' classification might be more descriptive and useful because it is based on fracture pattern and is concerned for achieving a stable fixation in femoral neck fracture in the young population. Pauwels' classification is based on the angle of femoral neck fracture relative to the horizontal axis $[14,15]$.

DHSs are used for internal fixation of fractures of the femoral neck and intertrochanteric region. The screw is a large cancellous lag screw that glides freely in a metal sleeve. The sleeve is attached to a side plate that is fixed to the lateral femoral cortex with screws [16]. Weight bearing causes the femoral head to become impacted on the femoral neck producing dynamic compression of the fracture. The shaft of the lag screw slides down the sleeve maintaining reduction of the fracture as compression occurs [16].

\section{Justification}

The use of the closed suction drain worldwide has had little or no impact on the outcome of the surgery concerning the infection rate. However, it is still practiced judiciously in all parts of the world as part of the general practice and individual expertise of each orthopedic surgeon. Sudan is just like the rest of the world in that manner, where the use of the suction drain is not based on evidence-based medicine and rather on personal experience and teaching. The only difference is that there is no published data concerning the outcome of the use of suction drains in orthopedics in Sudan, and especially on a large scale. Most of the studies encountered were encumbered with a small sample size that decreased the power of the study and failed to show statistical significance [10]. Therefore, this is the first study of its kind in Sudan to elucidate the need for the postoperative suction drain in orthopedics.

\section{Objectives of the Study}

\section{General}

To elucidate the need for the closed suction drainage in extracapsular fractures of the neck of femur treated by DHS in Sudan.

\section{Specific}

To compare the outcome of the patient with a closed suction drain vs. non-drained patient in terms of wound healing and complications. 


\section{Methodology}

\section{Study design}

This study is a non-randomized prospective cohort study to elucidate the need for closed suction drains in treatment of the fracture of the neck of femur via DHS in Sudan.

\section{Study area}

Khartoum Teaching Hospital is one of the major health facilities in the country located at the center of Khartoum, the capital city of Sudan. It has one of the largest orthopedics departments in the country and contains at least 8 orthopedic surgeons and as much as 30 more in training.

\section{Study sample}

The study sample consisted of 160 patients who underwent treatment for fractures of the neck of femur by DHS in KTH from the period of February to June 2016. All patients undergoing hip surgery were considered.

\section{Inclusion criteria included}

- $\quad$ Patients between the ages of 50 and 70 .

- $\quad$ Patient undergoing surgery for fracture of the neck of femur treated by DHS.

- $\quad$ Consenting patients.

The exclusion criteria included

- The presence of other co-morbid diseases such as DM, hypertension, renal impairment, coagulopathy, heart disease, or pathological fracture.

- $\quad$ Patients below the age of 50 .

- The presence of systemic or local infection prior to drainage insertion.

2 groups consisting of 80 patients each were selected in a nonrandomized fashion. One group contained the participants with the drain inserted and a control group that was matched in every way. The groups were homogeneous concerning the age group, the types of fractures and the ratio of male to female patients. The only factor differentiating these two groups was the presence or absence of the surgical drain.

\section{Study variables}

There were several independent variables in the study including the background variables like the age and gender, the presence or absence of the drain, the type of fracture and the duration of the drain insertion.

Dependent variables included the outcome of the patient i.e. wound, respiratory, cardiovascular and renal complications, the skin condition post-operatively, and the state of the wound when returning to the refer clinic 2 weeks later. Wound infection is defined as any infection of the surgical wound during the follow-up period of the study.

\section{Data collection}

The data was collected via a structured questionnaire* that was pre-coded. The questionnaire contained demographic data such as the gender and the age, the type and site of the fracture, duration of the drain insertion, and the duration of postoperative stay in the ward. The questionnaire also contained data concerning the post-operative complications i.e. wound infection, respiratory complications (e.g. pulmonary embolism, pneumonia), cardiovascular complications (e.g. heart failure, DVT), renal complications, and the development of bed sores. Last but not least, the questionnaire collects data about the wound if it was in fact infected and contains follow-up questions about the wound healing and the condition of the patient when they returned for the follow-up visit.

The data was collected via a research team trained by the primary investigator. The data collection began intra-operatively and ended in the refer clinic. A quality check control was performed on the field and the data checked for inconsistencies by the primary investigator.

\section{Data analysis}

The data was inserted into and analyzed using SPSS ${ }^{\mathrm{i}}$ version 18 (PASW) for Windows. Descriptive frequency analysis was done and Chi-square and Fischer's exact test were used to compare the differences in proportions between variables. The level of significance was set at 0.05 . Results and tables were displayed in appropriate table and figure format using Microsoft Excel 2010. Since this is a cohort study, relative risk was used to compare the risk in the ex-

*See Annex for a sample questionnaire

iSPSS: Statistical Package for Social Sciences@

Citation: Shareef S M Nada., et al. "A Prospective Study on the Efficacy of Closed Suction Drains in Fractures of the Hip Treated by Dynamic Hip Screw". Acta Scientific Orthopaedics 3.12 (2020): 58-67. 
posed (patients with drains) to the unexposed (patients without the drains).

\section{Ethical considerations}

Written consent was obtained and documented from each patient before including them in the study.

The Ethical Committee in the Sudan Medical Specialization Board (SMSB) has reviewed and approved of the study.

\section{Results}

160 patients were included in the study; $57 \%$ were male and $43 \%$ were female. These were divided homogenously between the 2 groups. The age range according to the inclusion criteria was 50 - 70 years old with the mean age being $61 \pm 2.8$. Regarding the types of fractures, 51\% (82) were intertrochanteric, 29\% (47) were subtrochanteric and 19\% (31) were basal cervical. Most of the fractures occurred on the patients' right limb (69\%) while $31 \%$ occurred on the left limb.

80 patients observed had a closed suction drain inserted and 80 patients did not receive surgical drains. Of the 80 patients who were drained, 50 (63\%) had the drain removed after 72 hours, $30(37 \%)$ had the drain removed by 48 hours and $0(0 \%)$ had the drain removed after 24 hours. Postoperatively, the duration of stay of the patients in the ward was 72 hours for $43 \%$ of cases and 5 days for $57 \%$ of cases.

Concerning the postoperative outcome, $10 \%$ of the entire population developed wound infections, 1.9\% developed respiratory complications, $15 \%$ developed CV complications, $15.6 \%$ had bed sores, $0 \%$ had renal complications, and $56.9 \%$ developed none of the complications.

Cross-tabulation of the 2 groups vs. the development of wound infections was done and showed that, among the patients with wound infections, $64.7 \%$ were from the drained group and $35.3 \%$ were from the non-drained group, but it was insignificant ( $\mathrm{p}$-value $>0.05$ ). However, the relative risk calculated showed that patients who received a drain postoperatively were 2 times more likely to develop a postoperative wound infection than patients who did not receive a drain, and it was statistically significant.

Regarding the respiratory complications, there was a high likelihood ratio $(\mathrm{p}=0.040)$ that the patients with drains developed respiratory complications when compared to the patients without drains.

Concerning the cardiovascular complications, cross-tabulation showed and increase in the rate of CV complications in the drained vs. the non-drained group, but it was statistically insignificant ( $p=$ 0.268).

Of the patients with bed sores, $68 \%$ were from the drained group and $32 \%$ were from the non-drained group with a p-value $>0.05$. This indicated that patients with drains were more likely to develop bed sores than patients without drains.

Of the patients with wound infections, 11 patients from the drained group and 6 patients from the non-drained group had superficial infections, had swabs taken, and received wound debridement.

Two weeks postoperatively, 73 patients (91\%) of the drained group and 78 patients (98\%) of the control group showed good healing and these results were statistically significant.

\begin{tabular}{|l|c|c|}
\hline & Frequency & Percent \\
\hline Male & 91 & 56.9 \\
\hline Female & 69 & 43.1 \\
\hline Total & 160 & 100.0 \\
\hline
\end{tabular}

Table 1: Gender distribution $(\mathrm{N}=160)$.

\begin{tabular}{|l|c|c|}
\hline & Frequency & Percent \\
\hline Intertrochanteric & 82 & 51.2 \\
\hline Subtrochanteric & 47 & 29.4 \\
\hline Basal cervical & 31 & 19.4 \\
\hline Total & 160 & 100.0 \\
\hline
\end{tabular}

Table 2: Type of fracture $(\mathrm{N}=160)$.

\begin{tabular}{|c|c|c|}
\hline & Frequency & Percent \\
\hline Right side & 111 & 69.4 \\
\hline Left side & 49 & 30.6 \\
\hline Total & 160 & 100.0 \\
\hline
\end{tabular}

Table 3: Fracture location $(\mathrm{N}=160)$. 


\begin{tabular}{|l|c|c|}
\hline & Frequency & Percent \\
\hline 24 hrs. & 0 & 0 \\
\hline 48 hrs. & 30 & 37.5 \\
\hline 72 hrs. & 50 & 62.5 \\
\hline Total & 80 & 100.0 \\
\hline
\end{tabular}

Table 4: Duration of drain insertion $(\mathrm{N}=80)$.

\begin{tabular}{|l|c|c|}
\hline & Frequency & Percent \\
\hline 3 days & 69 & 43.1 \\
\hline 4 days & 0 & 0 \\
\hline 5 days & 91 & 56.9 \\
\hline Total & 160 & 100.0 \\
\hline
\end{tabular}

Table 5: Duration of postoperative stay in the ward $(\mathrm{N}=160)$.

\begin{tabular}{|l|c|c|}
\hline & Frequency & Percent \\
\hline No & 91 & 56.9 \\
\hline Yes & 69 & 43.1 \\
\hline Total & 160 & 100.0 \\
\hline
\end{tabular}

Table 6: Postoperative complications $(\mathrm{N}=160)$.

\begin{tabular}{|l|c|c|}
\hline & Frequency & Percent \\
\hline Yes & 3 & 4.3 \\
\hline No & 66 & 95.7 \\
\hline Total & 69 & 100.0 \\
\hline
\end{tabular}

Table 7: Postoperative Respiratory complications $(\mathrm{N}=69)$.

\begin{tabular}{|l|c|c|}
\hline & Frequency & Percent \\
\hline Yes & 24 & 34.8 \\
\hline No & 45 & 65.2 \\
\hline Total & 69 & 100.0 \\
\hline
\end{tabular}

Table 8: Postoperative Cardiovascular system complications $(\mathrm{N}=69)$.

\begin{tabular}{|l|c|c|}
\hline & Frequency & Percent \\
\hline Yes & 25 & 36.2 \\
\hline No & 44 & 63.8 \\
\hline Total & 69 & 100.0 \\
\hline
\end{tabular}

Table 9: Development of bed sores $(\mathrm{N}=69)$.

\begin{tabular}{|l|c|c|}
\hline & Frequency & Percent \\
\hline Yes & 17 & 24.6 \\
\hline No & 52 & 75.4 \\
\hline Total & 69 & 100.0 \\
\hline
\end{tabular}

Table 10: Postoperative Wound infection? $(\mathrm{N}=69)$.

\begin{tabular}{|l|c|c|c|}
\hline \multicolumn{2}{|c|}{ Used } & \multicolumn{2}{c|}{ Closed suction drain } \\
\cline { 2 - 4 } & Not used & \\
\hline \multirow{2}{*}{ Type of wound } & Superficial & 11 & 6 \\
\cline { 2 - 4 } & Deep & 0 & 0 \\
\hline \multirow{2}{*}{ Was a swab taken } & Yes & 11 & 6 \\
\cline { 2 - 4 } & No & 0 & 0 \\
\hline \multirow{2}{*}{ Wound debridement } & Done & 11 & 6 \\
\cline { 2 - 4 } & Not done & 0 & 0 \\
\hline
\end{tabular}

Table 11: If there was wound infection: $(N=17)$.

\begin{tabular}{|l|c|c|c|}
\hline \multicolumn{2}{|c|}{ Used } & \multicolumn{2}{c|}{ Closed suction drain } \\
\cline { 3 - 4 } & Yot used & \\
\hline \multirow{2}{*}{ Stiches removed? } & No & 80 & 80 \\
\cline { 2 - 4 } & Good healing & 73 & 0 \\
\hline \multirow{2}{*}{$\begin{array}{l}\text { Wound healing } \\
\text { condition? }\end{array}$} & Poor healing & 7 & 2 \\
\hline
\end{tabular}

Table 12: Skin condition two weeks postoperatively: $(N=160)$.

\begin{tabular}{|l|c|c|c|c|}
\hline \multicolumn{2}{|c|}{ Used } & \multicolumn{2}{c|}{$\begin{array}{c}\text { Closed suction } \\
\text { drain }\end{array}$} & \multirow{2}{*}{ P value } \\
\cline { 3 - 4 } & Not used & & \\
\hline \multirow{2}{*}{ Wound infection? } & Yes & 11 & 6 & \multirow{2}{*}{0.200} \\
\cline { 2 - 4 } & No & 69 & 74 & \\
\hline \multirow{2}{*}{$\begin{array}{l}\text { Respiratory compli- } \\
\text { cations? }\end{array}$} & Yes & 3 & 0 & \multirow{2}{*}{0.040} \\
\cline { 2 - 4 } & No & 77 & 80 & \\
\hline \multirow{2}{*}{ CVS complications? } & Yes & 15 & 9 & \multirow{2}{*}{0.184} \\
\cline { 2 - 4 } & No & 65 & 71 & \\
\hline \multirow{2}{*}{ Bed sores? } & Yes & 17 & 8 & \multirow{2}{*}{0.050} \\
\cline { 2 - 4 } & No & 63 & 72 & \\
\hline
\end{tabular}

Table 13: (Wound infection, Respiratory complications,

CVS complications, Bed sores) * Closed suction drain cross-tabulation.

\begin{tabular}{|l|l|l|l|l|}
\hline \multirow{2}{*}{ Absent } & \multicolumn{2}{|l|}{$\begin{array}{l}\text { Postoperative } \\
\text { complications }\end{array}$} & \multirow{2}{*}{ P value } \\
\cline { 3 - 5 } & Present & & \\
\hline \multirow{2}{*}{ Closed suction drain } & Used & 34 & 46 & \multirow{2}{*}{0.000} \\
\cline { 2 - 4 } & Not used & 57 & 23 & \\
\hline
\end{tabular}

Table 14: Closed suction drain *Postoperative complications cross-tabulation. 


\begin{tabular}{|c|c|c|c|c|}
\hline \multicolumn{2}{|c|}{ Absent } & \multicolumn{2}{|c|}{$\begin{array}{c}\text { Postoperative } \\
\text { complications }\end{array}$} & \multirow{2}{*}{$\begin{array}{c}\text { P } \\
\text { value }\end{array}$} \\
\cline { 3 - 5 } & Present & & \\
\hline \multirow{2}{*}{ Drain insertion period } & 48 hrs. & 24 & 6 & \multirow{2}{*}{0.000} \\
\cline { 2 - 4 } & 72 hrs. & 10 & 40 & \\
\hline
\end{tabular}

Table 15: Drain insertion period * Postoperative complications cross-tabulation.

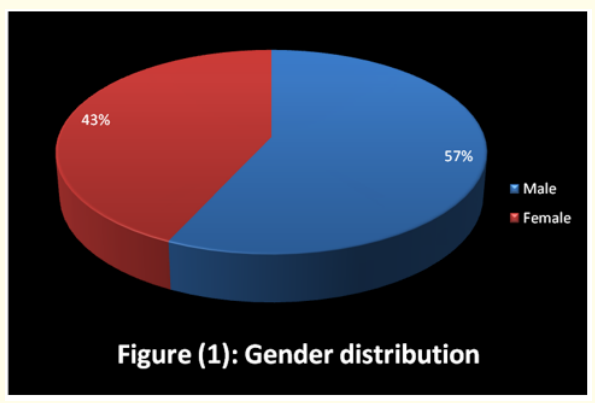

Figure 1: Gender distribution.

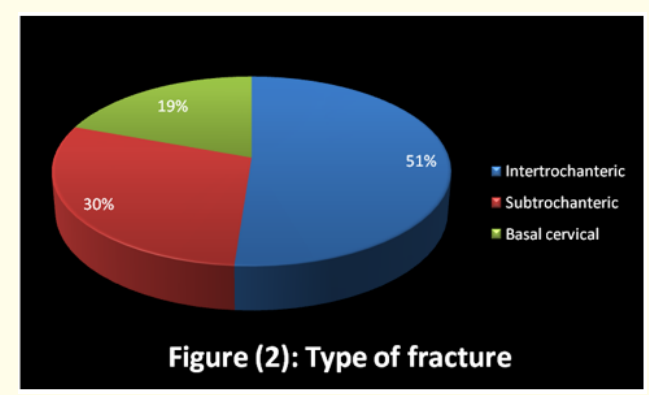

Figure 2: Type of fracture.

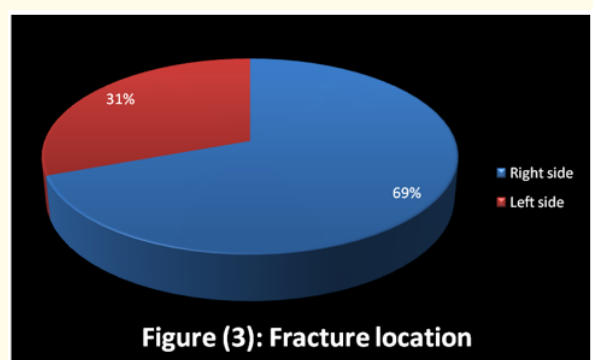

Figure 3: Fracture location.

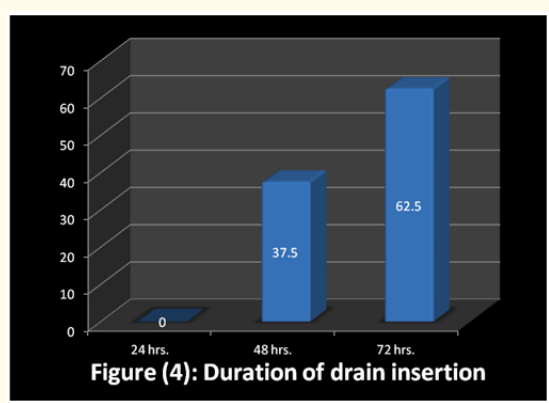

Figure 4: Duration of drain insertion.

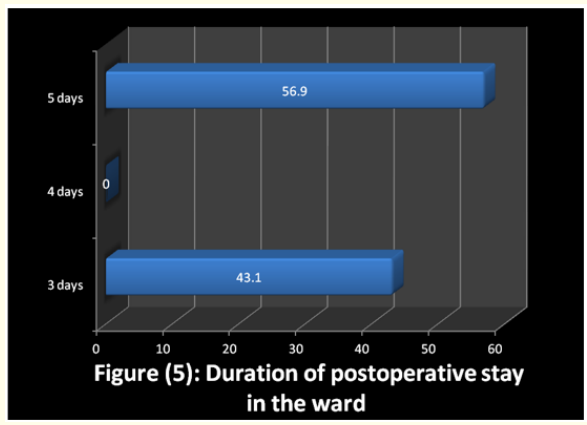

Figure 5: Duration of postoperative stay in the ward.

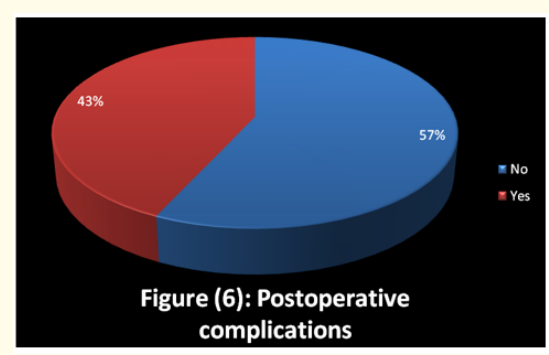

Figure 6: Postoperative complications.

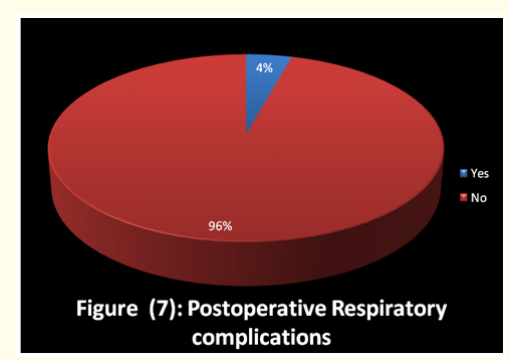

Figure 7: Postoperative respiratory complications. 


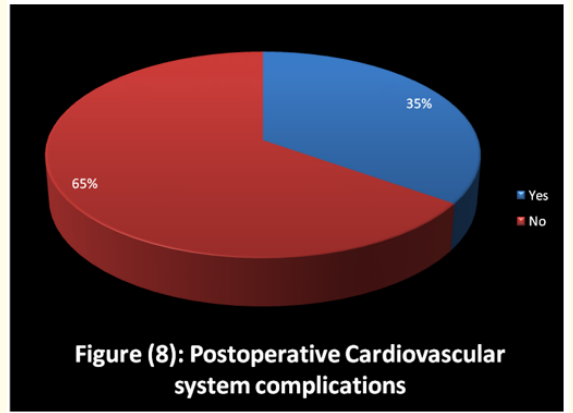

Figure 8: Postoperative cardiovascular system complications.

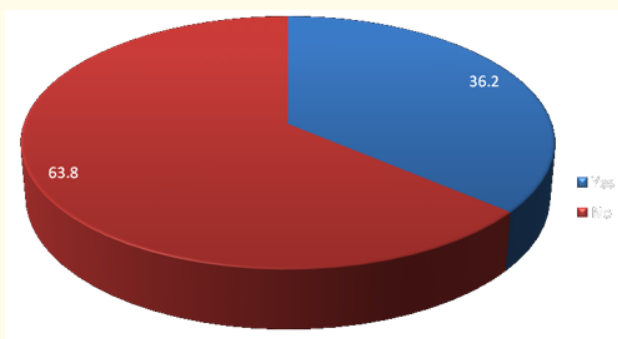

Figure 9: Development of bed sores.

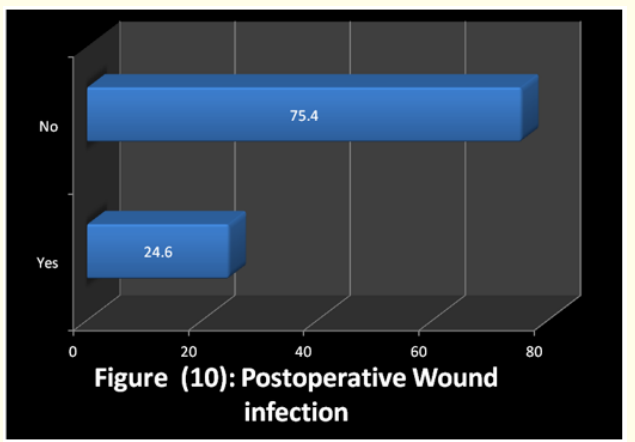

Figure 10: Postoperative wound infection.

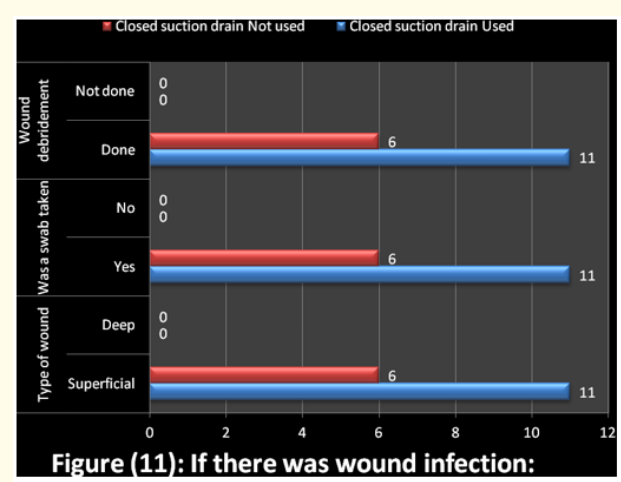

Figure 11: If there was wound infection.

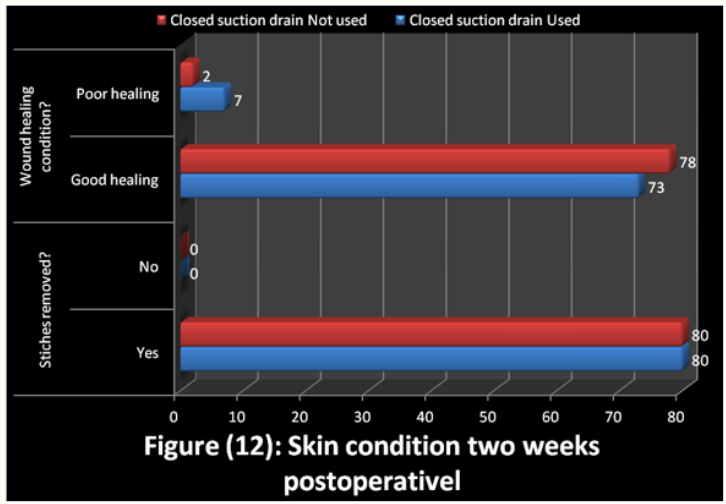

Figure 12: Skin condition two weeks postoperativel.

\section{Discussion and Conclusion}

Hip fractures in orthopedics have become a worldwide epidemic with an approximate 1.3 million fractures in 1990, which is expected to triple by the year 2050. This increase is predicted to be the highest in Africa [14]. In this light, it is essential to know the most efficient management possible for these types of fractures.

This is the first study of its kind that deals with the use of closed suction drains in extracapsular fracture neck of femur treated by DHS in orthopedic surgery. This study is unique in that it deals with an issue that has been a controversy for so long and has consistently lacked significant data [10]. Differences between the 2 groups - drained and non-drained - may show the necessity for the use of drains.

The use of drains has become a controversy in orthopedics and different observational studies have given inconsistent results, with some showing an increase while others a decrease in infection rate with the use of drains [10-12]. However, the use of closed suction drains has never been evaluated in a prospective randomized study. In prospective, nonrandomized studies done by Waugh., et al. (1961) [18] and Cruse., et al. (1973) [19], there was no difference found in infection rates whether a suction drain was used or not. A similar result was found with a retrospective study done by Reilly., et al. (1986) [20].

This is dissimilar to our study, where there was a RR of 2 (95\% $\mathrm{CI})$, which was highly statistically significant, regarding the infection rate in the drained group when compared to the non-drained group. This indicates that patients who receive a drain are twice more likely to develop a wound infection than patients without a drain.

However, this may be due to the fact that the drains have been left longer than the recommended time in this study. As pointed out 
by Overgaard and others [3-5], the recommended time for drain removal is 24 hours, with a maximum allotted time of 48 hours. After that, retrograde migration of bacteria through the drain itself occurs. In this study, $63 \%$ of the drained patients had the drain removed after 72 hours.

In this study, the postoperative complications in the drained group exceed those in the control group, with some of them showing statistical significance. There were no studies done that assessed other complications e.g. bed sores, respiratory and CV complications...etc.

The mean age for our study population was $61 \pm 2.8$, which is similar to a study conducted by Kim., et al. in 1998 [21], where the mean age was 64 . Of the 3 subtypes of extracapsular fractures of the neck of femur mention, 51\% were intertrochanteric fractures. Moreover, $69.4 \%$ of the patients had fractures on their right side rather than their left.

\section{Recommendations}

A meta-analysis conducted by Parker., et al. reviewed 16 studies regarding the use of closed suction drains and postoperative wound infections [9]. None of the studies provided statistically significant data regarding the postoperative wound infection associated with the use of drains. This study has provided significant data regarding the presence of postoperative complications with the use of closed suction drains in fractures treated by DHS, in which respiratory complications were the most significant.

Furthermore, the study reconfirmed the observations made by Chandretaya., et al. where the drains should be removed promptly if not by 24 hours, then at the most within 48 hours to avoid the risk of unnecessary infection [7]. Orthopedic surgeons practicing in Sudan should adhere to the recommended time frame.

Orthopedic surgeons should review their operative practice in terms of usage of surgical drains as it is causing more harm than good. Further research should be conducted in this area in a controlled randomized clinical trial.

\section{Bibliography}

1. Gaines RJ. "The Use of Surgical Drains in Orthopedics". Orthopedics 31.7 (2008): 702-705.

2. Akinsulire AT. "Use and Abuse of Drains in Surgery" (2009).
3. Overgaard., et al. "Closed suction drainage after hip arthroplasty: a prospective study of bacterial contamination in 81 cases". Acta Orthopaedica Scandinavica 64 (1993): 417-420.

4. Willemen D., et al. "Closed suction drainage following knee arthroplasty: effectiveness and risks". C/in Orthopedics 264 (1991): 232-234.

5. Willett KM., et al. "The effect of suction drains after total hip replacement". Journal of Bone and Joint Surgery 70B (1988): 607-610.

6. Drinkwater CJ and Neil MJ. "Wound drainage in arthroplasty". Journal of Arthroplasty 10 (1995): 185-189.

7. Chandrateya A. "To Drain or not to Drain Literature vs. Practice". The Royal College of Surgeons of Edinburgh 43 (1998): 404-406.

8. Drinkwater CJ and Neil MJ. "Optimal Timing of Wound Drains Removal Following Total Joint Arthroplasty". Journal of Arthroplasty 10.2 (1995): 185-189.

9. Parker MJ., et al. "Closed Suction Drainage for Hip and Knee Arthroplasty A Meta-analysis". The Journal of Bone and Joint Surgery 86A.6 (2004): 1146-1150.

10. Clifton R., et al. "Closed suction surgical wound drainage after hip fracture surgery: a systematic review and meta-analysis of randomized controlled trials". International Orthopedics 32.6 (2007).

11. Khanal GP., et al. "A study to evaluate the role of suction drains in orthopedic surgery". Health Renaissance 9.2 (2011): 91-94.

12. Tjeenk RM., et al. "Wound drainage versus non-drainage for proximal femoral fractures a prospective randomized study". Injury 36 (2005): 100-104.

13. Varley GW., et al. "Ultrasound assessment of the efficacy of wound drains". Journal of the Royal College of Surgeons of Edinburgh 39.2 (1994) 97-99.

14. Parker MJ. "Focus on intracapsular fractures of the femoral neck". British Editorial Society Journal of Bone and Joint Surgery 34 (2010): 36-38.

15. Varley GW and Milner SA. "Wound drains in proximal femoral fracture surgery: a randomized prospective trial of 177 patients". Journal of the Royal College of Surgeons of Edinburgh 40 (1995): 416-418.

16. Wheeless Clifford R III. Wheeless Textbook of Orthopedics. Sliding Hip Screws vs. Unstable Fractures. Data Trace Internet Publishing (2017). 
17. Crevoisier XM., et al. "Is suction drainage necessary after total joint arthroplasty? A prospective study". Archives of Orthopaedic and Trauma Surgery 117 (1998): 121-124.

18. Waugh TR and Stinchfield FE. "Suction drainage of orthopedic wounds". American Journal of Orthopaedics 43 (1961): 939-

946.

19. Cruse P J and Foord R. "A five year prospective study of 23,649 surgical wounds". Archives of Surgery 107.2 (1973): 206-210.

20. Reilly TJ., et al. "The use of postoperative suction drainage in total knee arthroplasty". Clinical Orthopaedics 20 (1986): 238242.

21. Kim YH., et al. "Drainage versus nondrainage in simultaneous bilateral total knee arthroplasties". Clinical Orthopaedics 347 (1998): 188-193.

\section{Assets from publication with us}

- Prompt Acknowledgement after receiving the article

- Thorough Double blinded peer review

- Rapid Publication

- Issue of Publication Certificate

- High visibility of your Published work

Website: https://www.actascientific.com/

Submit Article: https://www.actascientific.com/submission.php

Email us: editor@actascientific.com

Contact us: +919182824667

Citation: Shareef S M Nada., et al. "A Prospective Study on the Efficacy of Closed Suction Drains in Fractures of the Hip Treated by Dynamic Hip Screw". Acta Scientific Orthopaedics 3.12 (2020): 58-67. 